\title{
A RARE CASE OF RICHTER'S OBTURATOR HERNIA ON RIGHT SIDE IN A MALE PATIENT: A CASE REPORT AND REVIEW OF LITERATURE
}

\author{
Pankaj Kumar Verma1, Mukul Singh², S. R. Kala³, Sumit Sachan'4, Ashish Jaiswal5
}

\author{
${ }^{1}$ Associate Professor, Department of General Surgery, Dr. Susheela Tiwari Government Medical College and Associated Hospital, \\ Haldwani Dist., Nainital, Uttarakhand. \\ 2Post Graduate Resident 3rd Year, Department of General Surgery, Dr. Susheela Tiwari Government Medical College and Associated \\ Hospital, Haldwani Dist., Nainital, Uttarakhand. \\ ${ }^{3}$ Assistant Professor, Department of General Surgery, Dr. Susheela Tiwari Government Medical College and Associated Hospital, \\ Haldwani Dist, Nainital, Uttarakhand. \\ ${ }^{4}$ Assistant Professor, Department of General Surgery, Dr. Susheela Tiwari Government Medical College and Associated Hospital, \\ Haldwani Dist, Nainital, Uttarakhand. \\ ${ }_{5}^{5}$ Post Graduate Resident $2^{\text {nd }}$ Year, Department of General Surgery, Dr. Susheela Tiwari Government Medical College and Associated \\ Hospital, Haldwani Dist., Nainital, Uttarakhand.
}

\section{ABSTRACT}

Obturator hernia is a rare form of pelvic hernia accounting for $0.07-1 \%$ of all types of hernias and 0.2 to $1.6 \%$ of all the cases of small bowel obstruction having the highest mortality rate of all abdominal wall hernias between $13 \%$ to $40 \%$. A 65 -year-old male with small bowel obstruction related to Richter's obturator hernia found incidentally on exploratory laparotomy was treated effectively. A high suspicion for obturator hernia should be maintained when assessing a patient presenting with small bowel obstruction, particularly where intermittent symptoms or medial thigh pain are present. Rapid clinical and appropriate radiological assessment, followed by early surgery is critical for successful treatment.

\section{KEYWORDS}

Richter's-Obturator-Hernia-Rare Case

HOW TO CITE THIS ARTICLE: Verma PK, Singh M, Kala SR, et al. A rare case of Richter's obturator hernia on right side in a male patient: a case report and review of literature. J. Evolution Med. Dent. Sci. 2016;5(9):397-398, DOI: 10.14260/jemds/2016/91

\section{INTRODUCTION}

Obturator hernia is a rare form of pelvic hernia accounting for $0.07-1 \%$ of all types of hernias and 0.2 to $1.6 \%$ of all the cases of small bowel obstruction. ${ }^{1,2}$ having the highest mortality rate of all abdominal wall hernias between $13 \%$ to $40 \% .^{3}$ Patients can present with pain on medial aspect of thigh. ${ }^{4,5}$ recurrent intestinal obstruction or palpable mass on medial aspect of thigh. CT has best sensitivity and specificity for diagnosing an obturator hernia. ${ }^{6}$ Here, I present a rare case of Richter's obturator hernia on right side in a male patient operated in emergency and performed successfully.

\section{CASE REPORT}

A 65-year-old male presented in the Emergency Department with pain in right lower quadrant of abdomen, nausea, vomiting and constipation since 6 days. On examination his abdomen was soft, mildly distended with tenderness on right lower quadrant, but clinically had no masses and all hernial sites were intact. X-ray (Fig. 1) abdomen revealed dilated small bowel loops. After initial resuscitation patient was taken for emergency exploratory laparotomy. Abdomen was opened

Financial or Other, Competing Interest: None.

Submission 21-12-2015, Peer Review 14-01-2016,

Acceptance 20-01-2016, Published 01-02-2016.

Corresponding Author:

Dr. Mukul Singh,

Room No. 56, S. R. Hostel,

Dr. Susheela Tiwari Government Medical College

and Associated Hospital, Haldwani Dist.,

Nainital-263139, Uttarakhand.

E-mail: singhmukul3911@gmail.com

DOI:10.14260/jemds/2016/91 via midline incision. Richter's obturator hernia was found with content as part of circumference of ileal segment 6 inches proximal to I/C junction. Margins of herniated bowel loop was gangrenous and perforated. Bowel decompression was done from perforated ileal segment, abdominal defect was repaired primarily and loop ileostomy was done from perforated ileal segment. Abdominal cavity was closed in layers with placement of one pelvic drain. The patient recovered well and was discharged after 12 days of hospital stay without any complication. Patient was followed up regularly for 6 weeks followed by ileostomy closure. Patient is doing well and is followed up regularly at 30 days' interval.

\section{CONCLUSION}

A 65-year-old male with small bowel obstruction related to Richter's obturator hernia found incidentally on exploratory laparotomy was treated effectively. A high suspicion for obturator hernia should be maintained when assessing a patient presenting with bowel obstruction, particularly where intermittent symptoms or medial thigh pain are present. Rapid clinical and appropriate radiological assessment followed by early surgery is critical for successful treatment.

\section{REFERENCES}

1. Mantoo SK, Mak K, Tan TJ. Obturator hernia: diagnosis and treatment in the modern era. Singapore Medical Journal. 2009;50(9):866.

2. Lo CY, Lorentz TG, Lau PW. Obturator hernia presenting as small bowel obstruction. American Journal of Surgery. 1994;167:396-398. 
3. De Clercq L, Coenegrachts K, Feryn T, et al. An elderly woman with obstructed obturator hernia: a less common variety of external abdominal hernia. Journal Belge de Radiologie - Belgisch Tijdschrift voor Radiologi. 2010;93:302-304.

4. Hernia AJ. In: Maingot's abdominal operations. 10th ed. Zinner MJ, Schwartz SI, Ellis H, editors. Appleton \& Lange; London, GB: 1997. pp. 540-541.
5. Ho YH, Goh HS. Obstructed obturator hernia in 90 year olds-a management dilemma. Annals of the Academy of Medicine. 1991;20(3):410-411.

6. Shipkov CD, Uchikov AP, Grigoriadis E. The obturator hernia. Hernia: difficult to diagnose, easy to repair. Hernia. 2004;8:155-157. 